\title{
The Dynamics of Participation and Organisation in European Digital Rights Campaigning
}

\section{Yana Breindl}

*Göttingen Centre for Digital Humanities, Institute for Political Science, Georg-August Universität Göttingen, Platz der Göttinger Sieben 3, 37073 Göttingen yana.breindl@sowi.unigoettingen.de

Abstract: The paper examines the participation characteristics within internet-based collective action by analysing the case of digital rights campaigning. Drawing upon empirical findings from a case study (the "Telecoms Package" campaign, 2007-2009), we discuss how digital rights activists organise, collaborate and mobilise using websites, mailing lists, wikis and instant messaging channels. Participation is individualised and malleable. However, successful digital rights' campaigning requires political, technical and social skills. To intervene in EU policy-making, activists need technical and political expertise as well as technological skills to build up and maintain a campaigning infrastructure. As a result, and contrary to claims of inclusiveness and openness, digital rights campaigning is in fact dominated by a small group of highly specialised movement entrepreneurs who mobilise occasionally to demonstrate broader support to policy-makers. The emergence of internet-based campaigning does not necessarily equal to more inclusive forms of participation. However, it allows for the engagement of resource-poor actors in complex policy settings such as the EU.

Keywords: Digital Rights, Internet-based Campaigning, Organisation, Leadership, European Union, Collective action, Political participation

Acknowledgement: I would particularly like to thank the Wiener-Anspach foundation for supporting the writing phase of this research, the Oxford Internet Institute for hosting me and participants of an ECPR general conference "Internet and politics" panel for their insightful feedback.

nternet-based collective action is generally praised for being less hierarchical, more democratic and inclusive than traditional mobilising groups. The internet is considered to present a series of potentialities, among which the reduction of organisation and participation costs and the possibility to organise across space and time barriers (Earl \& Kimport, 2011). The decentralised end-to-end architecture of the internet is believed to mirror the ideological and organisational needs of current protest movements, the alter- 
globalisation movement being one of the most cited ones (Bennett, 2004; Castells, 2001; Van Laer \& Van Aelst, 2009). Online platforms provide spaces for large-scale collaboration that can result in the creation of public goods. Participation can be open and multiple, allowing for weak ties of cooperation, in a decentralised and asynchronous way. Each participant can choose his level of engagement and act autonomously (Fuster Morell, 2009). Attempts have been made to conceptualise these new forms of political action. Bennett and Segerberg (2012) propose the concept of connective action to characterise selforganising networks sustained by personalised communication. Organisational costs are reduced to the point where organisations are no longer necessary for sustaining protest. Personal memes travel more easily across social media than organisationally defined frames and can rapidly adapt to new political conditions. The internet itself is understood as a resource and archive of action repertoires and software that can be combined and recombined in action (Nielsen, 2009).

However, technologies are not inherently participatory; their use is shaped by cultural practices and political protest repertoires. In fact, a recurring characteristic of internetbased activism is the great variation in organisational structures relying on ICTs to promote social and political change (Bimber, Flanagin, \& Stohl, 2005). Internet-based activism should not automatically be reduced to social movement types of protest. Internet-based activists share common characteristics with social movements: they aim for social change, adopt identity-based network structures and the use of "unconventional" means of protest to challenge established elites with some degree of temporal continuity (Rucht, 2004; Snow, Soule, \& Kriesi, 2004). Social movements represent a certain "institutionalisation of particular struggles" (Cammaerts, 2008, p. 217), while ICTs clearly reduce the incentive to join established organisations (Earl \& Schussman, 2003). Furthermore, communication practices are increasingly difficult to separate from organisational structures within protest networks (Bennett, 2004). It is the campaign that becomes the foundation for activist networks, making information and communication practices central to the identity and existence of the group.

Digital rights activism is particular in that their political claims focus on the tools they use for mobilising and organising. They resort to particular types of actions including political coding (Breindl, 2011) or the voluntary provision of alternative communication channels (Hintz \& Milan, 2009). Their actions are informed by a desire to empower citizens through technology. Some groups operate outside of conventional policy processes while others act as "insiders" and actively engage in institutional processes (Hintz \& Milan 2009). Groups also diverge in terms of resources, strategies and organisational forms. Arguably, the recursivity of their actions - using the internet to protect the internet - allows them to be pioneers of open and flexible online campaigning. Research into digital rights activism is emergent with few academic studies having focused on digital rights as a globally networked struggle for the protection of civil liberties in the digital realm. Often, the term is used analogous to copyright-reform activism (Postigo, 2010) or alternative terms are used - e.g. ICT-policy activism by Löblich \& Wendelin (2012), access-to-knowledge by Krikorian \& Kapczynski (2010) or "grassroots tech groups" by Hintz \& Milan (2009). Digital rights is an umbrella term encompassing a 
series of internet-related topics that have often been researched separately: e.g. copyright (Horten, 2011), intellectual property rights (Haunss \& Shalden, 2011) or internet governance (Powell, 2012). In parallel, researchers have focused on "disruptive" forms of collective action such as hacktivism (Samuel, 2004), in particular Anonymous (Coleman, 2012), but less so on "insider" activists, who directly engage with parliamentary policyprocesses.

The present paper investigates how digital rights activists organise online, asking the question of who does what in online campaigning networks or whether participation is horizontal and equal among peers as often suggested by the literature. The next section focuses on the literature on how protest groups organise online before discussing the organisational structure of a digital rights campaign aiming for the defence of civil liberties and for an open internet at the European level.

\section{Organising online}

Internet sites connect like-minded actors, through lateral linkages (Foot, Xenos, Schneider, Kluver, \& Jankowski, 2009; Gibson \& Ward, 2000; Kavada, 2009). Activists use the internet to create ties with others through horizontal communication (Stein, 2009), across national and transnational spaces (Rosenkrands, 2004). Hyperlinks connect protest websites to one another, supporting internal and external organisation (Gibson \& Ward, 2000) and acknowledge the existence of other actors (Stein, 2009), be this to criticise or support their positions.

Building communities or networks of action is a central characteristic of protest groups and the way they use the internet. Biddix \& Park (2008) for instance showed the importance of ICTs in maintaining a networked community both in times of mobilisation and latency. Their example of the living wage campaign, the most known college-student campaign in the US launched by the Harvard Progressive Student Labour Movement to change labour policies, exemplifies how the internet was used to sustain the campaign through several student generations. The campaign initiated in 2001, at Harvard, involved political representatives and generated widespread awareness across the US media. The campaign website is since used as a support for similar protests long after its initiators graduated. It is a good example of how internet sites can sustain networks over time.

The variety of communities using the internet has increased exponentially since the development of the World Wide Web, bringing society's complexity and diversity online. Two cultural features are common to online communities following Castells (2001). They value free, horizontal communication, practising free speech at a global level. Unsurprisingly, this has become "one of the overarching values of the internet". Furthermore, most communities share a belief in what Castells calls "self-directed networking," defined as "the capacity for anyone to find his or her own destination on the Net, and, if not found, to create and post his or her own information, thus inducing a 
network" (Castells, 2001, p. 55). The principle is the organisational foundation for many internet-based communities.

Adopting a network structure is not inherently new to internet-based types of collective action. On the contrary, it is a characteristic of social movements well before the advent of the internet. In 1970, Gerlach \& Hine developed the SPIN model, refined by Gerlach (2001), arguing that social movements generally adopt a segmented, polycentric and integrated structure. If ICTs are only mentioned as an integrating aspect of social movements, Kavada (2008, p. 190) argues that "online communication is also related to the segmented and polycentric aspects of social movements". ICTs play a role in all three dimensions.

Protest movements are networked or integrated in the sense that "they form an integrated network or reticular structure through non-hierarchical social linkages among their participants and through the understandings, identities, and opponents these participants share" (Gerlach, 2001, p. 295). They are not limited but continually expand or contract as new members join or leave the network. Each participant is linked to other members of the movement. Linkages are maintained through gatherings and information technologies. It is on Netspaces that activists produce shared meanings and understandings of particular issues and elaborate new strategies (Stein, 2009). Most commonly, political networks use online spaces to interact, debate, achieve common meanings and coordinate collective action. Websites, Blogs, mailing lists, etc. constitute spaces of interaction, to learn, share, participate and build a common understanding of the issues at stake, supporting offline communication. "The parallel use of both online and offline means of communication establishes these protest campaigns as a hub through which disparate publics interconnect," argues Mattoni (2008, p. 106). Hyperlinks extend this space by linking to other types of actors on the internet, expanding the network. The internet allows for many-to-many communication, across time and space distances for a potential large audience and for the transmission of large amounts of information. However, the way the internet fosters debate and deliberation largely depends on how people use it. For Witschge (2007, p. 23), the internet offers unbounded spaces for interaction and possible anonymity "in an anonymous setting, fear of isolation, humiliation, harming others, not being liked, disapproval and others reasons traditionally seen as reasons for avoiding politics would be reduced". Unrestricted debate could take place, leading to the emergence of communities based on shared values and visions between citizens.

However, within political online spheres, "the degree of interactivity or real debate is often rather weak, as the forums and mailing lists are also used in order to inform or to mobilise", discussion "tend(s) to be dominated by those already politically active in the offline world and functions within a homogeneous ideological framework" (Cammaerts \& Van Audenhove, 2003, p. 191). Homophily is one of the characteristics of many online communities in which people gather with like-minded individuals in order to debate 
issues they are interested in. Sunstein $(2002,2009)$ refers to "echo chambers" to describe the reverberation of like-minded opinions within networked publics. The rapid proliferation of these niche audiences leads to "cyberbalkanisation" or the fragmentation of the internet into sub-parts that almost exclusively concentrate on their own interests. For Sunstein, this evolution harms democracy as individuals and groups are not exposed to each other's view online and only selectively retrieve information that conforms to their own worldview. From a deliberative perspective, Habermas (2006) argued that the sole democratic merit of internet debates is their possibility to undermine censorship in authoritarian regimes. In democratic public spheres, online discussions might benefit political communication when focusing on debates set by the quality press. For Habermas (2006, p. 423), electronic communication does however contribute to a fragmentation of "mass audiences into a huge number of isolated issue publics" or plays a "parasitical" role in deliberation.

In fact, previous social divisions are frequently reproduced online. Boyd (2011), for instance, pointed out that American teens reproduce social categories such as race and socio-economic status in their adoption of MySpace or Facebook. This analysis was confirmed by a study conducted by the Pew Research Center's Internet \& American Life Project (2009): Facebook users tend to be male, white and completed higher education while MySpace users are more frequently female, less educated and from ethnic origin. The balkanisation observed online is thus most likely a reflection of previous "offline" divisions. Concerning the particular case of political activism, counter-publics do cultivate an inward orientation, with a view to foster common understandings, identity and group solidarity. However, as political communities they also adopt an outwards orientation, towards a particular target, be it a nation state or within civil society itself (Breindl \& Houghton, 2010). From echo chambers, they can turn into powerful collective action, benefiting from their networked structure. What some scholars see as a dangerous fragmentation of an "imagined" public or audience does not exclude the cooperation between various protest groups and is not necessarily counter-productive for progressive movements.

Nonetheless, the internet can reinforce the segmented structure of collective action by allowing for highly flexible and independent forms of protest. Internet-based collective action facilitates autonomous forms of participation, embodied by a loose network of actors who share a common goal and set of values. Removing the need for large mobilising structures, the internet allows to efficiently aggregate small contributions and lowers the barriers for participation. As a result, there are increasingly "loosely organised, geographically dispersed, and locally engaged collections of activists" (Bennett, 2003, p. 5). Each participant can choose himself how much time, resources and effort he is willing to invest in a particular campaign or issue. Participation is flexible; it embraces a wide variety of individualised protest activities, such as joining a Facebook cause, signing a standard letter of support or contributing actively to a campaign wiki. The alterglobalisation movement for instance is characterised by a decentralised network structure 
described by Castells (2001, p. 142) as "hundreds, thousands of organisations and individuals, around the world, converging in some symbolic protests, then dispersing to focus on their own specific issues - or just vanishing, to be replaced by new contingents of newly born activists". This increased flexibility contributes to the success of some internet-based movements but it makes it more difficult to estimate what type and how many individuals are actually involved, regarding the fluidity of this type of protest forms (Dahlgren, 2004).

This flexible participation is non-hierarchical, in the absence of a centre or command structure in a polycentric manner. A decentralised form of organising is not necessarily different to social movement types of action that pre-existed the internet. Social movements are polycentric in that they are composed of many leaders or centres of leadership that are not organised hierarchically but in a "heterarchy". If spokespersons and leaders emerge within social movements, no individual or group effectively represents the entirety of the movement. Leaders generally emerge in particular situations, having to deal with particular challenges. They become leaders because they inspire others and "must continue to prove their worth and are often challenged by rivals" (Gerlach, 2001, p. 294). Non-professional individuals motivated by personal interests and relying on their own skills for undertaking movement activity, so-called "movement entrepreneurs" (Earl \& Schussman, 2003; Garrett, 2006), emerge as agents of mobilisation.

Claims have been made that actions of networked organisations will no longer be defined around prominent leadership, but by a common political agenda (Castells, 2001). Similarly, van de Donk et al. (Van de Donk, Loader, Nixon, \& Rucht, 2004, p. 9) suggest that the internet does not "demonstrate an inherent tendency to be concentrated and controlled in the hands of a few movement entrepreneurs". Far from being an equalising force, the internet may in fact reinforce leadership patterns. Email lists for instance offer privileged spaces for some persons to gain power and leadership, by taking control of the discussion (Kavada, 2006). Following Howard (2010), even if only a small number of internet users engage in contentious activities, notably in totalitarian states where internet access can be extremely limited, a few "brokers" suffice to inform a larger community and spark off wider protest actions. This is the case when the various segments and leaders composing a movement are integrated with each other. However, the decisions taken by such leaders are rarely binding to the participants of a movement. Next to questions of participation and inclusiveness, the paper thus also focuses on the role of leaders in internet-based activism.

\section{Methods}

The article is based on the case of the Telecoms package campaign and data gathered through in-depth interviews with activists and members and staff of the European parliament from February 2008 to April 2010. A caste study design has been chosen to provide a holistic account of the emergent phenomenon of digital rights campaigning, 
taking into account its "contextual conditions" (Yin, 2003, p. 13). To understand how activists proceed, organise and structure their exchanges, one needs to look at their community and culture, the political system they wish to influence and society at large. The goal is not to achieve generalisable results but to provide an insight into an emergent movement and "transferability" to similar cases (Pickard, 2007).

The particular case of the Telecoms package campaign has been selected because it was unfolding at the time of the research, offering insight into digital rights activism in its particular European context. The case is an "information-rich" example (Patton, 2002, p. 169), providing details of how activists organise and impact EU policy-making. The paper builds on a series of thirty-two in-depth interviews with core campaigners involved in the Telecoms package reform, that were selected following a purposive sampling strategy. Seventeen interviews were carried out with activists. The remaining fourteen involved members and staff of the European Parliament, the main targets of the campaign. MEPs, parliamentary assistants and political advisers from all political groups were interviewed as well as two administrators from the main committees that dealt with the package. The interviews were triangulated with an analysis of the websites and other campaigning material used as well as online and offline observations.

\section{The Telecoms package campaign}

The European Union amended its telecommunications law in 2009. The Telecoms reform package replaces existing law with two new directives and a regulation introducing a new European regulatory authority supervising the sector. More generally the package deals with issues of competition, radio and television spectrum and the integration and harmonisation of national telecommunications markets. In 2007, the proposed amendments were reviewed by the European Parliament and the European member states in the Council. Although the package did not deal with content regulation, digital rights activists raised concerns about two controversial issues in the package: first, so-called "copyright hooks" in the shape of amendments urging ISPs to comply with online copyright enforcement (Horten, 2011), references to "lawful content" and direct references to intellectual property rights, were strikingly similar to measures preconized by the French HADOPI draft law that aimed at introducing graduated response $(\mathrm{Yu}, 2010)$ in France. Second, amendments were introduced to strengthen traffic prioritisation and to promote a vertical integration model of the internet to sell premium content under preferential conditions by distinguishing between the services offered. Activists rejected these in the defence of "net neutrality", referring to the indiscriminate routing of packets over the internet, considered as the foundation of the open "end-to-end" internet architecture. They succeeded in generating high awareness of digital rights issues and supported a series of amendments that substantially affected the package (see Breindl, 2012; Horten, 2011). The following sections focus on how the variety of groups engaged in the campaign organised online and offline. 


\subsection{Multiple groups}

The Telecoms package reform acted as a catalyst for generating a coalition and collaboration across Europe. Attention to the package was raised at the chaos communication congress (24C3), Europe's largest hacker meeting, in Berlin in December 2007. In the absence of an active European umbrella group, national associations were sensitised to the controversial issues in the package. A European mailing list was officially established in February 2008, allowing access only to trusted activists, generally the representatives of national associations. The mailing list was intended to resolve failed attempts to coordinate more effectively on a European level, notably during the data retention directive (2006/24/EC). A wiki on the package was set up by activists but not used substantially during the campaign. Other wikis were created but did not federate a large community of contributors. Everybody agreed on increasing European coordination. However, without a clear threat and many issues to deal with at the national level, coordination faltered at first.

In March 2008, a French digital rights advocacy group, la Quadrature du Net, emerged, operating both at the national and European level. Its founders were active on digital rights issues for some years and raised concerns about copyright and net neutrality issues in the Telecoms package. Over the twenty months of the campaign, they found allies in a series of European countries, receiving advise from an U.S. Electronic Frontier Foundation advocate, collaborating with the German internet politics platform Netzpolitik.org or activists engaged in the data retention working group (AK Vorrat), the Britsh non-profit association Open Rights Group, the Spanish free culture group eXgae (rebaptised X.net since), the Italian online platform ScambioEtico or the Swedish internet cluster Telecomix/WeRebuild. These groups provided important information and mobilisation relays for the core leader of the campaign: the French Quadrature du Net (QdN). Attempts were made to forge alliances with like-minded industry groups but distrust was high on the side of the activists, most of whom preferred to operate independently. However, from a very early stage, activists established good connections with assistants and members of the European Parliament that were essential in explaining and providing insider information about the policy process.

$\mathrm{QdN}$ itself is a heteroclite cluster of autonomous individuals. The core campaigners know each other personally, but contributors come from various regions in France and are sometimes anonymously involved. The core team has clear linkages and affiliations to the French free software movement. But not all are committed free and open source software supporters, especially the ones who joined once the campaign was on-going. All are sensitive to free and open source software, access-to-knowledge and free culture issues however. The loose coalition of European digital rights groups took shape because activists shared a common set of values they had previously defended and saw threatened again in the Telecoms package, and because they made use of similar communication and information tools. 


\subsection{Integrative factors}

The campaign built and extended upon the historic interactions born out of previous digital rights initiatives and shared beliefs. Activists consider the internet a common good that needs to be defended against regulatory or corporate encroachments. For the people who joined the campaign, the common denominator was the defence of a free and open internet against what was perceived as an external threat. What gathered people in instant messaging channels was the belief in the internet as a positive transformative force for society that needed to be defended against "abusive" regulation. The protection of their "natural habitat" constituted a necessity, not a choice.

Past struggles, especially the "No Software Patents" campaign (Breindl, 2011), were essential in providing an example of a successful campaign. More importantly, the intervention on the so-called "Bono report", a non-binding European Parliament initiative on cultural industries, provided a common language that was debated and agreed on through an international private mailing list. An amendment supported by activists in the report led to the framing of "graduated response" (three-strikes was largely preferred by activists) as being not proportional, not effective nor dissuasive and that it might violate human rights. In parallel, they campaigned for the recognition of the internet as favouring democracy, education and participation. The self-image of the community is essential and persisted after previous struggles.

The perceived threats to civil liberties and the internet in the package fostered panEuropean collaboration. Activists interested in the package established linkages and spaces of interaction, central to coordinating the campaign. Contacts were established thanks to previous connections, targeting those considered as most useful for the challenge at stake. Personal networks were solicited and old contacts re-contacted. Lateral linkages are established through a network of like-minded individuals, groups, and associations around the issue as testifies $\mathrm{QdN}$ 's core campaigner:

"There are the ones with who we are in contact, and the ones who are in contact with the ones we are in contact. You know it's rhizomatic. . . [. . . I It's literally like the Internet, it's the interconnection of networks, it's a network of networks. And that's how it's effective, by multiplying links, by multiplying the strands, so that if one falls over, we can pass by the others. So there is no active attempt to build this. [. . . I It's when something happens, I call that person, I send an email to that other one, I send our press releases to all mailing lists where I know that ten or so people will see it. It works or it doesn't. Actually, we don't tell people to engage themselves; somehow we show them the example. We release something and if people consider it's bad enough, it's important enough and that we are right, well they will translate it for their country and take care of it" (itv. 22*).1

\footnotetext{
${ }^{1}$ Interviews with one asterisk are translations from French, with two asterisks from German. All translations are by the author.
} 
The campaign consisted in a distributive effort, involving a wide range of digital rights groups that operated in a highly decentralised and autonomous manner. Activists engaged on the parts of the campaign they felt most competent in, resulting in a certain specialisation of activities that was also coloured by national sensitivities and the national political contexts of that time. It came as no surprise that the leader of the campaign was a French advocacy group, which had to deal with similar issues at the national level and would thus target two interrelated policy-processes. The internet allowed for collaboration to go beyond those national borders:

"You find volunteers from everywhere and you work with people in countries that you've never been to necessarily and certainly you never need to meet those people. Sometimes you meet them after you finish the campaign you know. It's that way around and that's fine" (ORG campaigner).

ICTs were used as spaces of coordination and collaboration. QdN's website constituted the central platform for distributing information to interested individuals. Mailing lists and IRC chats served the important function of negotiating common meanings and understandings. RSS fluxes were used to receive each other's press releases and updates. Everyone could configure what information to follow and one's level of engagement.

\subsection{Participation Dynamics}

The groups that engaged most on the Telecoms package are informal internet-based structures. The goal of these groups was to remain flexible and without official statutes, in order to be more reactive and not spend vital resources on keeping the organisation running. The idea is to be easily adaptable to new situations, to be as agile and effective as possible. The people composing QDN, for instance, were described as having "complicated personal trajectories, tomorrow they might be leaving to do something else" (QdN analyst, itv. 13*). It is thus essential that the structure allows for a maximal renewal of volunteers and leaders. Being an association "would be a waste of time, energy, money and efficiency", argues another QdN co-founder (itv. 27*), because their work is too specialised and too unknown to a wider public for attracting a large membership; in a time of fading political engagement through traditional mobilising structures. Being a de facto association permits to focus on the campaign alone, which sustains the activist networks without the need for a central organisation (Bennett, 2004). In groups like QdN or Telecomix, no formal membership exists, as explains a Telecomix campaigner:

"We don't have a membership. You cannot become a member of this. You can just participate. It's a really decentralised structure. We don't even have leaders or we don't make decisions. We just act very directly, launch a campaign, and everything goes very quickly, but there are no formal decisions or formal processes on what to do tomorrow. What happens tomorrow just happens. In that sense, it's extremely decentralised and also I think in one sense a bit fragile, because there are no formal structures, once we stop talking in the chat room, it's over. It could actually end any minute. But I don't think it will! I think that people are very motivated to work with these issues right now" (Telecomix/WeRebuild activist). 
The Telecoms package ad hoc coalition can be best described as functioning in concentric circles of participation (Breindl \& Gustafsson, 2011). At its centre (figure 1), core campaigners are the leaders of the campaigning effort. They are the ones who set up email lists or wikis, create new applications and are highly involved in the analysis and face-to-face lobbying of MEPs. They are supported by voluntary contributors, who are inscribed on discussion lists and follow the IRC channel, not only actively engaging in the discussion but also analysing legislative texts, correcting press releases, editing the campaign wiki, spreading information online and creating new tools. With growing involvement over time, they gain access to online campaigning spaces. A third circle is composed of occasional contributors, people who follow closely what core campaigners do. They perform tasks such as translating documents or press releases, cleaning up the wiki or helping out with reviewing the press coverage of their activities. They generally don't have access to login-protected sites, although they could if they requested to. A fourth circle consists of followers, who are inscribed on the discussion list and possibly engage in particular actions, but do not actively contribute to the organisation of the campaign itself.

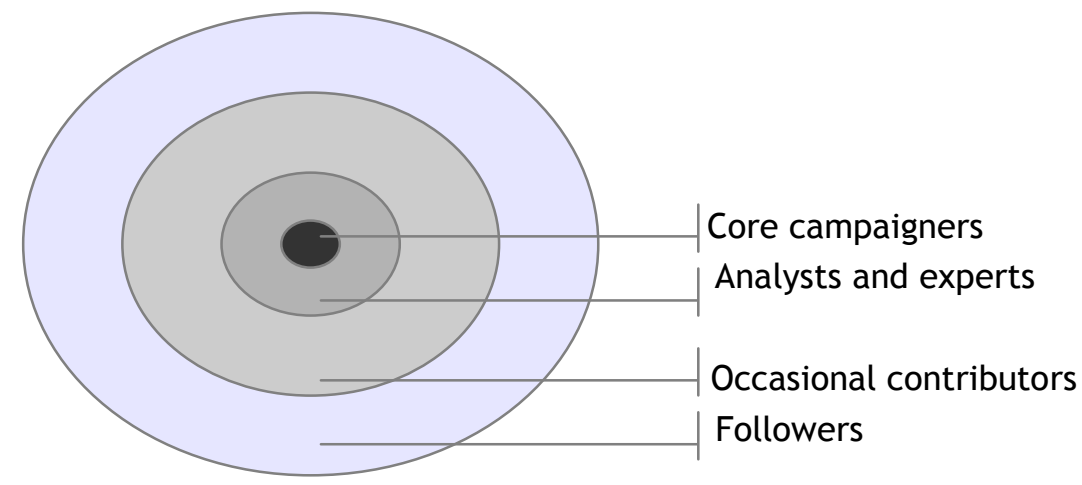

Figure 1: Concentric circles of participation

Participation is fluctuating within the informal internet-based groups composing the ad hoc coalition. It varies depending on how much time a person can make free and what interests that person holds. Naturally, a certain specialisation occurs following the skills and competences of the participants. Core campaigners are in charge of following narrowly the political process, analysing and orchestrating the campaign. Core supporters are analysts of legislative texts and parliamentary amendments, holding a certain technical or political expertise. They regularly participate in the correction of press releases and analysis. Occasional contributors participate from time to time while a very imprecise group of people follows the campaign, without directly engaging in it. Members are autonomous from the organisation itself, some collaborating independently. Many activists are involved in a series of associations, but try to keep these struggles and issues separate from each other - at least when acting publicly. Digital rights groups function without formal positions, similarly to free and open source software 
communities. Each person does what he/she is good at, and a spontaneous division of labour occurs:

"Anyone can do anything. [...] If someone has a good idea and presents it, and more people think it's a good idea, it usually gets done. Then of course anyone who thinks they are good at doing whatever they're gonna do, will do and then we end up with something good. [...] It's kind of a natural selection of what we do. If enough people find it's a good idea, they will do it, and then it's there, I mean for everyone's use. I think that has been a very successful way of working so far" (Telecomix/WeRebuild activist 2).

Other digital rights groups also welcome spontaneous involvement and new propositions. However, they are more pessimistic about the "natural selection" process of voluntary-based campaigning. When focusing on a concrete objective, such as opposing the Telecoms package, one needs to count on a small group of very engaged campaigners, asserts a QdN analyst:

"The overwhelming majority of us are really volunteers. [...] It's exhausting. One of the big problems is that, and it's the same in free software or any ecosystem of a collective to work, there has to be a small group of people who are ultra-full time. In free software, it's not complicated. It's also necessary but not complicated because it's often done by people who have a status, or who do it for one or two years because it's a personal project, or because they can lean on a company that finances their operation on that project partly. In digital activism, it's a little more complicated to make sure that there are people and for them it's terribly wearing. And for the rest... well, you can easily be somebody who does really useful things for La Quadrature du Net one hour a week. But it only works if there are people like [the main campaigner] who are really working on it. I don't even count the amount of time that is" (itv. $\left.13^{*}\right)$.

Leadership was thus essential for coordinating a broad range of autonomous activists and to convince them to engage in the campaign.

\subsection{Centres of leadership}

Different types of leadership structures were practised depending on the groups. The case of Telecomix illustrates a completely decentralised architecture, which has been described by the group as "IRCocracy or friendocracy" and as a "sociocyphernetic organism". Core campaigners on the Telecoms package are considered as "supernodes" in their respective networks. In peer-to-peer networks, supernodes are nodes that also function as a proxy server, a component in a decentralised architecture that characterised, for instance, the file-sharing site Kazaa. In political activism, supernodes are the persons who are most frequently present in the IRC channels and discussion lists and hold expertise on the issues discussed. Activity is not only distributed, but highly autonomous and independent. Independence from political power centres, such as political parties for instance, was also maintained throughout the campaign - even if close contacts were maintained with collaborators of some political groups at the EU level, and parties at the national level. "Without a chief, everybody is a chief" was the saying of activists. The distributed nature of interactions is believed to allow for reconfigurations and the 
emergence of some persons as centres or hubs of interactions. In the case of QdN, a leading campaigner left the group at the early campaigning stage and was replaced by another campaigner whom he had previously worked with.

No formal hierarchy existed within most digital rights groups' active on the Telecoms package, with the exception of more formal groups, such as EFF and the ORG. However, strong leadership existed also in informal internet clusters. Decisions are taken by doing, leadership is believed to emerge "naturally": the more one does and is skilled in doing, the more he/she is likely to emerge as the leader of the group. The rule of thumb is that any person is encouraged to contribute, and those who bestow a considerable amount of time, and show the strongest analytical skills, emerge naturally as leaders. Nonetheless, leadership proved necessary to provide the impulsion for campaigning activities. Those who were involved from the beginning, or simply performed most of the work and acted as leaders, emerge as benevolent "dictators", as claims a QdN activist:

"A de facto initiative enjoys freedom of movement and even of decision, which is sometimes in contradiction to the principles we defend. We defend democratic principles, of democratic voting and so on whereas what I explained to you about la Quadrature, it's a question of circles that have grown more and more, and where the decision is taken by a few persons at the start and enlarged afterwards. But actually the hard core acts as a dictator at the outset" (itv. 20*).

Qdn rapidly emerged as the leader, the "hub in the middle" (Netzpolitik.org, itv. 40**), that generated the impulsion for campaigning alerts and mobilisation. Their central position wasn't contested for most of the campaign, other groups followed their lead because they spend most time on it and knew the package best. An FFII-Germany activist recalls: "They really hacked into it, analysed everything and engaged with it and they were really the most influential force throughout all three readings!" (itv. 41**). Others followed their initiatives in a more or less coordinated manner, although different actions could emerge in parallel:

"Being a coordination space, it sounds like we are pulling the strings, which is absolutely not true. But we were a space of coordination, I think, notably, for the first reading of the Telecoms package. But there were other moments where there were much more distributed initiatives among groups, coalitions that were made by other people but always dialogue, trying to be coherent and complementary" (QdN analyst, itv. 13*).

Distributive campaigning resulted in groups acting autonomously and independently from one another. During the last phase of the campaign, the conciliation procedure, QdN's leadership was contested by other activists as disagreements emerged on the strategy to adopt (Breindl, 2012). This lack of coordination and agreement destabilized the overall campaigning effort and lead to the adoption of a weak compromise amendment on graduated response. Nonetheless, for most of the campaign, central campaigners or "supernodes" provided information and tools to allow others to use it as they see fit:

"Everyone does it his way, takes a piece and elaborates around. Others will copy-paste the English [press release]. Others will translate it from the first to the last letter. What's important, is that everyone reuses it. It's, as I said, a toolbox. If some feel like translating it, 
they translate. If some feel like interpreting and analysing it, well they interpret and analyse it. That's how it works" (QdN campaigner, itv. 12*).

"We want to give them the means [to engage]. We can't give them financial means but at least we give them the intellectual means, the arguments, the communication tools to do it. At least those which we use, we place them at the disposition of everybody. That's work for us too because, of course, you have to translate it" (QdN supporter, itv. 27*).

Groups would pick up the information produced by the core of five or six campaigners, who worked on a daily basis on the Telecoms package, and would ask their followers to spread it further and act on it. While supporters spread the information produced by a core team of campaigners, the latter benefited from increased time to concentrate on the lobbying effort. Supporters were also invited to participate online across spatial boundaries.

"It is not unusual that we hold the analysis together, to build a shared document using tools for sharing documents like Etherpad or Co-ment [online text editing tools], so you can share your ideas and make a real-time analysis all together. It's like, we were in a room all together and you could see the changes on any document in real time, and you can exchange critical information in real time, and this is very effective, because it's just like to be face-to-face" (ScambioEtico campaigner, itv. 29).

For some campaigners, internet activism was, however, characterised by certain obstacles. Online collaboration necessitated digitally skilled persons who could help maintain the internet-based campaigning infrastructure.

\subsection{Hurdles to online collective action}

For a Telecomix/WeRebuild campaigner who held a background in humanities and journalism, technical skills are central in digital rights campaigning:

"Our infrastructure, which is completely internet-based, depends on the fact that we have people who actually know how to set up an IRC server, or how to program a big website,... In one sense, it's the skills that come from people who are, usually they are not educated, but they are hackers, many hackers are part of us and many of us joined, I joined, for example, the hacker spaces movement that is growing in Sweden, even though I don't know much about computers. I like the whole idea of opening up technological systems" (itv. 39).

The most engaged persons in the campaign were thus not representative of "lay" citizens. The campaign included a relatively homogeneous set of activists, most of them being male, of Caucasian origin, often holding a university background in computer science, living in urban areas and generally highly skilled in the use of computers - those who were not contributed good connections to the political scene or the media. All interviewees agreed that women constituted the exception in digital rights groups. It was not just a question of gender, but of general diversity. The absence of women was considered to be more of a societal issue, than a characteristic of the movement, pointing to the low number of women engaged in computing in general, and free and open source 
software in particular. ${ }^{2}$ The three women interviewed - because previous interviewees were explicitly asked to reference women - occupied key positions within the movement: one as an ally inside the European Parliament, the two others acting as spokespersons and central campaigners for a French and Spanish group. None of them came from an engineering background.

The geek and hacker mentality is very common among the activists interviewed, manifest in the way they talk, dress and carry a laptop around wherever they go. They recognise others who behave in similar ways, and speak a common language as equals. Some groups are characterised by a particular vocabulary, often using programming language to make sense of complex political processes. Participation in such groups is said to be open, anybody can join. It is a meritocracy, a person being judged upon his input and expertise. Despite activists' egalitarian philosophy, issues of gender and diversity that stem from the hacker and computing culture are not resolved in the activist realm. Within digital rights activism, the few women involved rarely come from a technological background. They are "exceptional women" in the sense that they feel at ease within a dominantly male community, and hold the political expertise to significantly contribute to it. All of the women encountered are very conscious of their particular situation. However, few activists actively tried to involve more women and "non-geeks" in the campaign.

Another challenge for the movement consisted in reaching out beyond the internet. If information sharing and document exchanges are facilitated by the use of ICTs, trust was considered as not being "scalable", in the same manner than information would rapidly spread through the network. The need to consolidate relationships and convince MEPs demanded for face-to-face meetings and participation in public debates. For a Netzpolitik.org campaigner, interactions between "nerds" were not always fruitful online and more frequent face-to-face meetings could have avoided some conflict:

"[There are these] typical cases, you have people on mailing lists who are a little gooey or unfriendly. When you happen to meet them personally, you discover that they are totally peaceful, nice, friendly people. But in this nerd culture, many lack the social polish so to speak, to have the necessary political finesse. That can quite rapidly lead to so-called flame wars, which are really unnecessary, and which could be avoided if we were all at the same place but being at one place means investing lots of time and sometimes also money to get there. So the internet is the alternative" (Netzpolitik.org campaigner, itv. 40**).

Hence, face-to-face meetings were rare, but allowed central campaigners to get to know each other personally. Real-life encounters are perceived as favourable between central campaigners, to exchange information and most of all build trust networks and increase future collaboration:

"When you have such a personal access to somebody, and when you can also just go for a beer at night, then you can speak more efficiently about things than if you were doing it very intensively over the Net" (Netzpolitik.org campaigner, itv. 40**)

2 In 2004, there were $28 \%$ women involved in proprietary software development. At the same time, less than $2 \%$ of FLOSS developers were women (FLOSSPOLS, 2006). 
These encounters complemented intense online discussions throughout the twenty month long campaign. Different groups operated differently but worked towards a common goal, that was repeatedly constructed through mailing lists and IRC chats. Overall, interviewees expressed a sense that there is a movement emerging on digital rights issues within and beyond the EU.

\section{Discussion and concluding remarks}

Distributive campaigning resulted in groups acting autonomously and independently from one another. This held the advantage of being able to adapt frames and discourses to local audiences and prevent long and sometimes difficult decision-making debates. However, it also led to dissatisfaction, misunderstandings and incoherencies in the overall campaigning strategy, as has been exemplified by the Telecoms package campaign's divisions throughout the conciliation procedure, resulting in difficulties to influence the policy-process towards the end of the process. The main findings are summarised in Table 1.

\begin{tabular}{|c|c|c|c|}
\hline Segments & Integration & Leadership & Challenges \\
\hline $\begin{array}{l}\text { Multiple groups } \\
\text { Specialisation and division } \\
\text { of labour } \\
\text { National sensitivities } \\
\text { No formal membership } \\
\text { structures } \\
\text { Connection with decision- } \\
\text { makers } \\
\text { Distrust of industry } \\
\text { representatives }\end{array}$ & $\begin{array}{l}\text { Offline meetings } \\
\text { Intense online interaction } \\
\text { Shared beliefs and values } \\
\text { Common language through } \\
\text { repeated engagement with } \\
\text { policy-process } \\
\text { Culture of doing } \\
\text { Self-image of a broad, } \\
\text { capable and skilled network } \\
\text { Shared threat and enemy } \\
\text { Flexible and autonomous } \\
\text { participation }\end{array}$ & $\begin{array}{l}\text { Concentric circles of } \\
\text { participation } \\
\text { Types of leaderships: } \\
\text { "friendocracy", } \\
\text { "benevolent dictators" } \\
\text { Decisions taken by } \\
\text { doing } \\
\text { Leadership through } \\
\text { presence and } \\
\text { involvement } \\
\text { Coordination space } \\
\text { and toolbox }\end{array}$ & $\begin{array}{l}\text { Reliance on techno-savvy } \\
\text { participants } \\
\text { Exhaustion } \\
\text { Resources } \\
\text { Conflict management } \\
\text { Dependency on a small group of } \\
\text { highly active campaigners } \\
\text { Tension democratic values - lack of } \\
\text { decision-making structures } \\
\text { Low diversity and difficulty to reach } \\
\text { out beyond the internet }\end{array}$ \\
\hline
\end{tabular}

Table 1: Summary of key findings

A gap exists between the activists' discourses promoting inclusiveness and open participation, and their actual practices. Core activists are not representative of "ordinary" citizens, but possess strong digital skills, understand the internet's infrastructure and hold programming and technical abilities. The campaign posed questions of diversity. Although the aim was to involve as many persons as possible, campaigners and supporters were generally young, educated men, holding specialised technical knowledge. Following Sunstein (2002; 2009), the risk of homogeneous groups is that their views are amplified through repeated interaction with like-minded persons. This poses a challenge to democracy that builds upon common experiences, and the exposure to diverse topics, persons and ideas. As individuals generate their own personalised information environment through internet tools, there is a risk of group polarisation.

An analysis of how MEPs perceived the Telecoms package campaign (Breindl, 2012) shows that some conservative representatives judged the campaign as simplistic, and the 
activists' perspective as dogmatic. Group discussions inside the activist networks did reinforce predefined positions, because those who joined the discussion were generally agreeing with what was said. However, activists regularly discussed, criticised and analysed official and institutional positions, news reports and studies by their opponents. They engaged with other groups that held different positions and, most importantly, brought to the policy-making process an alternative view on the issues at stake.

Throughout the campaign, they maintained an outward orientation. No doubt, the activist groups would gain from broadening their supporter base and integrate further perspectives. However, one of the reasons that the main campaigners held (or acquired in the course of the campaign) technical, legal and/or political skills, has to do with the difficulties of integrating the policy-making process. MEPs would acknowledge citizen input but to act on it, they expected facts, analysis and expertise. To be efficient, the activist network favoured the emergence of skilled leaders, to the detriment of diversity. Internet-based activism is thus not necessarily more inclusive and egalitarian as, similarly to other types of activism, it requires technical skills and issue-specific expertise to be efficient.

Contrary to repeated claims of inclusiveness and the lack of strong leadership in internet-based collective action, evidence from the case study suggests that even in highly decentralised movements, strong leadership emerges. This is not only the case in this particular community. Evidence from the global justice movement confirms that basic technologies, such as email lists, can constitute new sources of power and leadership inside networked groups (Kavada, 2008). The technological structure of the internet may be decentralised and open, yet the social structures that use it can remain somewhat more vertical, as leaders emerge and tend to increase their power over time.

Networks do not suppose that all of nodes are equal, only that communication flows more horizontally. Within the various clusters composing digital rights networks, some individuals hold more power than others, generally the most active ones. Horizontal exchanges of communication do not signify equality in access to information, editing rights or division of labour. The case illustrates the continuous importance of "movement entrepreneurs" (Earl \& Schussman, 2003; Garrett, 2006), individuals motivated by personal interests and relying on their own skills for undertaking movement activity. The network structure allows members to reconfigure rapidly and reorganise, in the case of the absence of an active campaigner for example. Leadership is organised in a heterachic and meritocratic manner. Heterachy signifies that individuals enjoy an equal position in the network, privileges and power relations can be reversed and redistributed, depending on the needs of the system. Those who hold dominant positions do so because of their merit and/or their continuous involvement and contribution to the network. Activists who are highly engaged are likely to emerge as leaders, even though others might provide more skilled input. Various decision-making centres co-exist and can be challenged by rivals. Internet-based protest networks thus resemble social movement types of collective action in that they are segmented, polycentric and integrated structures (Gerlach \& Hine, 1970; Gerlach, 2001). 
Instead of becoming a member, supporters manifest their approbation of the campaign through active engagement. Participation is fluctuating, depending on who has the time and the motivation to engage. Skilled participants are valuable resources, and once they are integrated in the network, they are not as readily replaced as campaigners might wish for. Barriers of participation are lowered because supporters can contribute small efforts that can be effectively aggregated through online tools. However, citizen input is only efficiently leveraged if a core group of highly involved campaigners decides on the general direction of the campaign, possibly without consulting its supporter base. Decision-making is informal and autonomy is promoted. Indirect feedback loops exist as campaigners' decisions will impact upon the number of participants who join the struggle. Efficiency is most important to digital rights activists, at the expense of deliberation and common decision-making contrary to other movements that privilege inclusiveness and discussion.

The paper is critical of generalized and enthusiastic claims of inclusiveness in internetbased activism. While it is true that organisational structures are more fluid and flexible than formal organising structures, this evolution is not entirely disruptive of how protest actors organised prior to the internet. Future research needs to investigate the way in which power and leadership are negotiated within internet-based protest groups, preferably from a comparative perspective. The lack of diversity might be attributed to the technical nature of digital rights activism. The analysis could thus be usefully complemented by further insights into how movements operate in a diversity of domains.

\section{References}

Bennett, W. Lance. (2003). New Media Power: The Internet and Global Activism Contesting Media Power: Alternative Media in a Networked World. Oxford: Rowman \& Littlefield Publishers.

Bennett, W. Lance. (2004). Global Media and Politics: Transnational Communication Regimes and Civic Cultures. Annual Review of Political Science, 7, 125-148.

Bennett, W. Lance, \& Segerberg, Alexandra. (2012). The logic of connective action. Digital media and the personalization of contentious politics. Information, Communication $\mathcal{E}$ Society, 15(5), 739-768.

Biddix, J. Patrick, \& Park, Han Woo. (2008). Online networks of student protest: the case of the living wage campaign. New Media \& Society, 10, 871-891.

Bimber, Bruce, Flanagin, Andrew J., \& Stohl, Cynthia. (2005). Reconceptualizing Collective Action in the Contemporary Media Environment. Communication Theory, 15(4), 365-388.

Boyd, Danah. (2011). White flight in networked publics? How race and class shaped American teen engagement with MySpace and Facebook. In Lisa Nakamura \& Peter Chow-White (Eds.), Digital race: An anthology (pp. 203-222): London: Routledge.

Breindl, Yana. (2011). Promoting openness by "patching" European directives: internet-based activism \& EU telecommunication reform. Journal of Information, Technology and Politics, $8(3), 346-366$.

Breindl, Yana (2012). Assessing success in internet campaigning. Information, Communication \& Society, pp. 1-22. Available at http:// www.tandfonline.com/doi/abs/10.1080/1369118X.2012.707673

Breindl, Yana, \& Gustafsson, Nils. (2011). Leetocracy: Networked Political Activism or the Continuation of Elitism in Competitive Democracy. In Daniel Araya, Yana Breindl \& Tessa 
J. Houghton (Eds.), Nexus: New Intersections in Internet Research (pp. 193-212). New York: Peter Lang.

Breindl, Yana, \& Houghton, Tessa J. (2010). Techno-Political Activism as Counterpublic Spheres: Discursive Networking within Deliberative Transnational Politics? Paper presented at the ICA Conference, Singapore.

Cammaerts, Bart. (2008). Critiques on the Participatory Potentials of Web 2.0. Communication, Culture \& Critique, 1(3), 358-376.

Cammaerts, Bart, \& Van Audenhove, Leo. (2003). ICT-Usage among Transnational Social Movements in the Networked Society: to organise, to mediate \& to influence: The European Media and Technology in Everyday Life Network 2002-2003, Key deliberable.

Castells, Manuel. (2001). The Internet Galaxy: Reflections on the Internet, Business, and Society: Oxford University Press.

Coleman, Gabriella (2012). Our Weirdness is Free, The Logic of Anonymous - online army, agent of chaos, and seeker of justice. Triple Canopy.

Dahlgren, Peter. (2004). Foreword. In Wim B. H. J. Van de Donk, Brian Loader, Paul G. Nixon \& Dieter Rucht (Eds.), Cyberprotest: new media, citizens, and social movements. London: Routledge.

Earl, Jennifer, \& Kimport, Katrina. (2011). Digitally Enabled Social Change: Activism in the Internet Age. Cambridge, MA: MIT Press.

Earl, Jennifer, \& Schussman, Alan. (2003). The new site of activism: On-line organizations, movement entrepreneurs, and the changing location of social movement decision-Making. Research in social movements, conflicts and change, 24, 155-187.

Foot, Kirsten A., Xenos, Michael, Schneider, Steven M., Kluver, Randolph, \& Jankowski, Nicholas W. (2009). Electoral web production practices in crossnational perspective. the relative influence of national development, political culture, and web genre. In Andrew Chadwick \& Philip N. Howard (Eds.), The Routledge Handbook of Internet Politics. London: Routledge, pp. 40-55.

Fuster Morell, Mayo. (2009). Online creation communities for the building of digital commons: Participation as an eco-system? Paper presented at the International Forum on Free Culture and Knowledge, Barcelona, Spain.

Garrett, R. Kelly. (2006). Protest in an Information Society: a review of literature on social movements and new ICTs. Information, Communication \& Society, 9(2), 202-224.

Gerlach, Luther P. (2001). The Structure of Social Movements: Environmental Activism and its Opponents, Networks and netwars: The future of terror, crime and militancy, pp. 289-310.

Gerlach, Luther P., \& Hine, Virginia H. (1970). People, Power, Change: Movements of Social Transformation Indianapolis: Bobbs-Merill.

Gibson, Rachel, \& Ward, Stephen. (2000). A Proposed Methodology for Studying the Function and Effectiveness of Party and Candidate Web Sites. Social Science Computer Review, 18(3), 301319.

Habermas, Jürgen. (2006). Political Communication in Media Society: Does Democracy Still Enjoy an Epistemic Dimension? The Impact of Normative Theory on Empirical Research1. Communication Theory, 16(4), 411-426.

Hintz, Arne, \& Milan, Stefania. (2009). At the Margins of Internet Governance: Grassroots Tech Groups and Communication Policy. International Journal of Media \& Cultural Politics, 5, 2338.

Horten, Monica. (2011). The Copyright Enforcement Enigma: Internet Politics and the 'Telecoms Package', London: Plagrave Macmillan.

Howard, Philip N. (2010). The Digital Origins of Dictatorship and Democracy: Information Technology and Political Islam: Oxford University Press.

Kavada, Anastasia. (2008). Decentralization and Communication: Email Lists and the Organizing Process of the European Social Forum, Cyber Conflict and Global Politics, London: Routledge, pp. 188-204. 
Kavada, Anastasia. (2009). Engagement, Bonding and Identity Across Multiple Platforms: Avaaz on Facebook, YouTube and MySpace. Paper presented at the ECPR General Conference, Potsdam, Germany.

Kneip, Veronika \& Niesyto, Johanna. (2007). Interconnectivity in the 'public of publics'. The example of Anti-Corporate Campaigns. Paper presented at the Changing politics through digital networks: The role of ICTs in the formation of new social and political actors and actions, University of Florence, Italy.

Krikorian, Gaeille \& Kapczynski, Amy (2010), Access to knowledge in the age of intellectual property. New York: Zone Books.

Löblich, M. \& Wendelin, M. (2012) 'ICT policy activism on a national level: Ideas, resources and strategies of German civil society in governance processes', New Media \& Society, 14(6): 899-915

Mattoni, Alice. (2008). ICTs in national and transnational mobilizations. tripleC, 6(2), 105-124.

Nielsen, Rasmus Kleis. (2009). The Labors of Internet-Assisted Activism: Overcommunication, Miscommunication, and Communicative Overload. Journal of Information Technology \& Politics, 6(3), 267-267.

Patton, Michael Quinn. (2002). Qualitative Research and Evaluation Methods. Thousand Oaks, CA: Sage Publications.

Pew Research Center's Internet \& American Life Project (2009). Adults and social network websites, report, Available at: http://pewinternet.org/Infographics/Growth-in-AdultSNS-Use-20052009.aspx

Pickard, Alison J. (2007). Research methods in information. London: Facet Publishing.

Postigo, Hector (2010) 'Information communication technologies and framing for back fire in the digital rights movement: The case of Dmitry Sklyarov's advanced e-book processor', Social Science Computer Review, 28(2): 232-250.

Powell, A. (2012). 'Emerging issues in Internet Regulation: The unstable role of WikiLeaks and cyber-vigilantism', In Brown, I. (ed.), Research Handbook on Governance of the Internet, Cheltenham: Edward Elgar (forthcoming).

Rosenkrands, Jacob. (2004). Politicizing Homo economicus: analysis of anti-corporate websites, W. van de Donk, B. Loader, P. Nixon, \& D. Rucht (Eds.), Cyberprotest. New Media, citizens and social movements, London: Routledge, pp. 57-76.

Rucht, Dieter. (2004). The quadruple ' $\mathrm{A}$ ': media strategies of protest movements since the 1960s, in W. van de Donk, B. Loader, P. Nixon, \& D. Rucht (Eds.), Cyberprotest. New Media, citizens and social movements, London: Routledge, pp. 29-56.

Samuel, Alexandra W. (2004). Hacktivism and the future of political participation. PhD thesis, Harvard Univer- sity, Department of Government, Cambridge, MA. Retrieved from http://www.alexandrasamuel.com/ general/now-available-hacktivism-the-future-ofpolitical-participation

Snow, Davis A., Soule, Sarah A., \& Kriesi, Hanspeter. (2004). Mapping the Terrain, The Blackwell Companion to Social Movements, Oxford: Wiley-Blackwell, pp. 3-18.

Stein, Laura. (2009). Social movement Web use in theory and practice: a content analysis of US movement websites. New Media \& Society, 11(5), 749-771.

Sunstein, Cass R. (2002). Republic.com, Princeton University Press.

Sunstein, Cass R. (2009). Republic.com 2.0, Princeton University Press.

Van de Donk, Wim B. H. J., Loader, Brian, Nixon, Paul G., \& Rucht, Dieter. (2004). Cyberprotest. new media, citizens and social movements. London: Routledge.

Van Laer, Jeroen, \& Van Aelst, Peter. (2009). Cyber-Protest and Civil Society: the Internet and Action Repertoires of Social Movements, Handbook on Internet Crime, Portland: Universia Press, pp. 230-254.

Witschge, Tamara. (2007). (In)difference online: The openness of public discussion on immigration. University of Amsterdam.

Yin, Robert K. (2003). Case study research: Design and methods. 3rd ed. London: Sage Publications.

Yu, Peter K. (2010). The Graduated Response. Florida Law Review, 62, 1373-1430. 


\section{About the Author}

Yana Breindl

Yana Breindl is a researcher at the Göttingen Centre for Digital Humanities and the Institute for Political Science at the Georg-August Universität Göttingen in Germany. Focusing on the interrelation of ICTs and society, she is interested in how digital technologies are sites of power struggles for various social groups. From November 2011 to June 2012, she was a post-doctoral fellow at the Oxford Internet Institute, University of Oxford and worked on discourse networks surrounding mandatory internet blocking proposals across Europe. She holds a B.A., M.A. and Ph.D from the Université Libre de Bruxelles, where she carried out research on European digital rights campaigning. Currently, she carries out a comparative study of internet blocking regulation in liberal democracies and has published extensively on the internet and collective action, digital rights and internet research. 